\title{
Inflation Uncertainty, Output Growth Uncertainty and Macroeconomic Performance
}

\author{
Stilianos Fountas, ${ }^{*}$ Menelaos Karanasos $\dagger$ and Jinki Kim $\$$
}

*Department of Economics, University of Macedonia, Thessaloniki, Greece $\uparrow$ Business School, Brunel University, Uxbridge, UK

(e-mail: menelaos.karanasos@brunel.ac.uk)

†angwon Development Research Institute, Chuncheon-si, South Korea

\begin{abstract}
We use a bivariate generalized autoregressive conditionally heteroskedastic (GARCH) model of inflation and output growth to examine the causality relationship among nominal uncertainty, real uncertainty and macroeconomic performance measured by the inflation and output growth rates. The application of the constant conditional correlation GARCH(1,1) model leads to a number of interesting conclusions. First, inflation does cause negative welfare effects, both directly and indirectly, i.e. via the inflation uncertainty channel. Secondly, in some countries, more inflation uncertainty provides an incentive to Central Banks to surprise the public by raising inflation unexpectedly. Thirdly, in contrast to the assumptions of some macroeconomic models, business cycle variability and the rate of economic growth are related. More variability in the business cycle leads to more output growth.
\end{abstract}

\section{Introduction}

Since the early 1980s, there has been a tremendous improvement in macroeconomic performance in industrialized and developing countries. Krause (2003) reports that in a cross section of 63 countries, mean inflation has fallen from approximately $83 \%$ in the pre- 1995 period to approximately $9 \%$ in the latter half of the 1990 s. Furthermore, both inflation and output growth have become more stable. Cecchetti and Krause (2001) report that, 
in a sample of 23 industrial and developing countries, the average country experienced a decline in both inflation and output variability in the 1990s compared with the 1980s. A second fact reported in the Cecchetti and Krause (2001) study is that there seems to exist a trade-off between inflation and output variability. A number of interesting issues arise from the above findings. First, is the reduction in average inflation related to the reduction in inflation uncertainty, and if so, is the causality between the two variables bidirectional? Secondly, is it true that a reduction in inflation and, therefore, inflation uncertainty can have a favourable impact on the rate of economic growth, as predicted for example by Friedman (1977)? Thirdly, can a more stable and less volatile output growth rate lead to more output growth?

This study analyses the empirical relationship among four important macroeconomic variables: average inflation, output growth, nominal (inflation) uncertainty and real (output growth) uncertainty. Our objective is to examine all possible effects among these four variables using time-series data for the G7. In this respect, we attempt to provide answers to the above three questions and, therefore, test for the empirical relevance of several theories that have been advanced on the relationship between inflation, output growth, real and nominal uncertainty. These theories include: first, the Cukierman and Meltzer (1986) hypothesis that Central Banks tend to create inflation surprises in the presence of more inflation uncertainty; secondly, the Black (1987) hypothesis that increasing output uncertainty leads to more output growth; thirdly, the Taylor (1979) effect that predicts a trade-off between inflation and output variability and hence uncertainty.

Following the pathbreaking work on the autoregressive conditional heteroskedasticity $(\mathrm{ARCH})$ approach, the prevalent approach to measuring uncertainty in the macroeconomics literature has been the conditional variance of a macroeconomic series. To test for the relationship between macroeconomic uncertainty and indicators of macroeconomic performance, such as inflation and output growth, one can use a simultaneous or a two-step approach. Under the simultaneous approach, an ARCH-in-mean (ARCH-M) model is estimated with the conditional variance equation incorporating lags of the series, thus allowing simultaneous estimation and testing of the bidirectional causality between the series and the associated uncertainty. Under the two-step approach, estimates of the conditional variance are obtained from the estimation of an ARCH model and then these estimates are used in running Granger-causality tests to examine the causality between macroeconomic performance and uncertainty.

In this paper, we examine the theoretical issues raised above with the use of a bivariate generalized ARCH (GARCH) model that allows for the measurement of uncertainty about inflation and output growth by the respective conditional variances. GARCH methods to examine these issues 
have recently been applied by many researchers. The studies by Grier and Perry (1998), Henry and Olekalns (2002), Fountas, Ioannidis and Karanasos (2004a), Conrad and Karanasos (2005), and Karanasos and Kim (2005) focus almost exclusively on the empirical relationship between any of the following three: (i) inflation and inflation uncertainty, (ii) output growth and output growth uncertainty and (iii) nominal and real uncertainty. Grier and Perry (2000) and Grier et al. (2004) use a simultaneous approach and examine a richer, though not complete, set of hypotheses. However, these studies employ only US data. Fountas, Karanasos and Kim (2002) test for a complete set of hypotheses using a constant conditional correlation model but their focus is limited to Japanese data. An exception is Fountas and Karanasos (2006). They use the two-step approach in a univariate GARCH framework and examine a limited set of hypotheses using data for the G7. To cover these gaps in the existing literature we use monthly data on the G7, a bivariate GARCH approach, and a two-step procedure to examine all the possible causal relationships among inflation, output growth, and the respective uncertainties that are predicted by economic theory.

The paper is structured as follows. Section II presents the theoretical macroeconomic implications concerning the relationship among the four variables of interest. Section III summarizes the empirical literature to date. Section IV lays out our econometric model and section V reports and discusses our results. The last section contains our main conclusions and draws some policy implications.

\section{Theory}

\subsection{The effect of macroeconomic uncertainty on inflation and output growth}

Macroeconomists have placed considerable emphasis on the impact of economic uncertainty on the state of the macroeconomy. They seem to agree that the objectives of monetary policy are inflation and output stabilization around some target levels. Exogenous shocks to the economy that generate uncertainty about the inflation rate and output (or its growth rate) tend to cause a deviation of these variables from their desired values and hence necessitate some policy response. Friedman (1977) argues that inflation uncertainty causes an adverse output effect. This outcome is based on the idea that uncertainty about future inflation distorts the allocative efficiency aspect of the price mechanism. More specifically, inflation uncertainty affects both the intertemporal (through its effect on the interest rate) and intratemporal (through its effect on relative prices in the presence of nominal rigidities) allocation of resources. 
The effect of inflation uncertainty on output growth works also through its impact on investment. Some theoretical literature on investment (Pindyck, 1991) focuses on the irreversibility aspect of investment and considers current investment as giving up the option to invest in the future. Hence, the value of this lost option represents the opportunity cost of an investment project. Inflation uncertainty increases the uncertainty regarding the potential returns of investment projects and therefore provides an incentive to delay these projects, thus contributing to lower investment and output growth. ${ }^{1}$ In sharp contrast, Dotsey and Sarte (2000), using a cash-in-advance framework, obtain a rather puzzling result: more inflation uncertainty can increase output. This result is based on a precautionary motive and the assumption of risk-averse agents: more inflation uncertainty raises savings and hence investment and growth.

Uncertainty about future inflation also affects the average rate of inflation. However, the direction of the effect is ambiguous from a theoretical point of view. Cukierman and Meltzer (1986) assume that agents face uncertainty about both the rate of money supply growth (and hence inflation) and the policy-maker's objective function. In a Barro-Gordon set up, because of the existing inflationary bias, the monetary authority surprises the agents by setting an unexpectedly high money supply growth rate. According to the authors' argument, in the presence of more inflation uncertainty the behaviour of the monetary authority leads to more inflation. In contrast, Holland (1995) claims that the monetary authority, when faced with more inflation uncertainty in the economy will contract the growth rate of money supply and hence reduce inflation (and the associated uncertainty) in order to counteract the negative welfare effects of inflation uncertainty on the economy. This is the so-called 'stabilizing Fed hypothesis' and postulates a negative effect of inflation uncertainty on inflation.

A number of theories have been put forward to examine the impact of output uncertainty on real growth. In a nutshell, the sign of such an effect is ambiguous. First, according to business cycle models, there is the possibility of independence between output variability and growth which occurs when the determinants of the two variables are separate. In particular, these models assume that output fluctuations around its natural level arise from price misperceptions. In contrast, output growth is determined by real factors such as technological changes. A second finding of the theoretical literature is that of a positive effect of real uncertainty on output growth that can be justified by a number of economic theories. For example, according to Black (1987), investments in riskier technologies will be pursued only if the expected return

\footnotetext{
${ }^{1}$ Evidence of a negative impact of inflation uncertainty on a primarily irreversible investment like R\&D is provided by Goel and Ram (2001).
} 
on these investments (average rate of output growth) is large enough to compensate for the extra risk. Blackburn (1999), in a study based on endogenous growth caused by learning-by-doing, shows that business cycle volatility raises the long-run growth of the economy. ${ }^{2}$ Finally, according to Pindyck (1991), the negative relationship between output volatility and growth arises from investment irreversibilities at the firm level. More recently, Blackburn and Pelloni (2005) have used a stochastic monetary growth model with three different types of shocks (technology, preference and monetary) that have permanent effects on real growth because of wage contracts and endogenous technology. The authors show that output growth and its variability are negatively correlated irrespective of the type of shocks causing fluctuations in the economy.

Finally, real uncertainty may also affect the rate of inflation. Devereux (1989) extends the Barro-Gordon model by introducing endogenous wage indexation. He considers the impact of an exogenous increase in real uncertainty on the degree of wage indexation and the optimal inflation rate delivered by the policy-maker. He shows that more uncertainty about output growth reduces the optimal amount of wage indexation and induces the policy-maker to engineer more inflation surprises. Hence, the testable implication of the model is that more real uncertainty should lead to a higher average rate of inflation. ${ }^{3}$

\subsection{The relationship between inflation and output growth}

Mean inflation and output growth are interrelated. Although the traditional short-run Phillips curve implies that an increase in output above its natural level would result in inflationary pressures, another strand of the literature analyses how a rise in the output growth can affect the rate of inflation. Briault (1995) argues that there is a positive relationship between growth and inflation, at least over the short run, with the direction of causation running from higher growth (at least in relation to productive potential) to higher inflation. For simplicity, in what follows, we refer to this positive effect as the 'Phillips curve' effect.

\footnotetext{
${ }^{2}$ Blackburn and Pelloni (2004) in a stochastic monetary growth model show that the correlation between output growth and its variability is a function of the type of shocks buffeting the economy. The study concludes that the correlation will be positive (negative) depending on whether the real (nominal) shocks dominate.

${ }^{3}$ The prediction of Devereux's theory regarding the positive causal effect of output uncertainty on the inflation rate is borne out also in a recent paper by Cukierman and Gerlach (2003). It is possible that more uncertainty about output growth leads to a lower inflation rate. Higher output uncertainty implies lower inflation uncertainty (the Taylor effect discussed below) and hence a lower inflation rate (the Cukierman and Meltzer hypothesis).
} 
Useful summaries of the macroeconomic literature on the inflation-growth relationship can be found in Briault (1995), Bruno and Easterly (1996), Haslag (1997), Temple (2000) and Klump (2003). Economists in the structuralist tradition have sometimes argued that moderate inflation rates are potentially beneficial for growth. Overall, it would now be hard to find much support for the view that inflation can raise growth (Temple, 2000). The theoretical studies generally find that a rise in inflation either results in slower growth or has no impact on the growth rate. Some models have produced insignificant long-run inflation-output growth effects (e.g. Dotsey and Sarte, 2000), while at least an equally diverse group of models have produced significant and negative inflation-growth effects. In particular, Gylfason and Herbertsson (2001) present a simple model of the interaction of inflation and output growth. Their model indicates that, although a wide variety of outcomes is possible, inflation via saving, financial development and the government budget deficit tends to deter growth in the long run. Klump (2003) points out that inflation can lead to a reduction of the aggregate elasticity of factor substitution. He suggests several microeconomic justifications for such an influence, which in turn can help to explain the negative link between inflation and growth. Gillman and Kejak (2005) show that a broad array of endogenous growth models, with different usage of physical and human capital and different exchange technologies, can all generate significant negative effects of inflation on growth.

\subsection{Output uncertainty and inflation uncertainty}

There is a consensus among macro-theorists to express the ultimate objectives of the monetary authority in terms of deviations of inflation and output from their target levels. Nevertheless, one may argue that Central Banks are also interested in minimizing the variability of inflation and output around their target levels (see, e.g. Cecchetti and Krause, 2001). Taylor (1979) shows that a trade-off between the two variabilities exists, it is consistent with rational expectations and sticky prices, and implies no long-run trade-off between the levels of inflation and unemployment (the Taylor effect). Fuhrer (1997) employs a structural model of optimal monetary policy chosen by minimizing a loss function that depends on the variances of inflation and output (expressed as deviations from their targets) and derives the variance trade-off. Cecchetti and Ehrmann (1999) show that aggregate supply shocks create a trade-off between nominal and real variability. Policy-makers, depending on their preferences, i.e. their degree of aversion towards inflation and output variability, can choose a point along this trade-off. Clarida, Gali and Gertler (1999) also derive a short-run inflation-output variability trade-off that represents an efficient frontier. 
In contrast to the Taylor effect, Logue and Sweeney (1981) claim that nominal uncertainty can have a positive impact on real uncertainty. A higher inflation rate makes it more difficult for producers to distinguish between nominal and real demand shifts, thus leading to more relative price variability. Assuming this relative price variability leads to more producer uncertainty, the upshot will be more variability in real investment and economic activity. Finally, in Devereux's (1989) model, inflation uncertainty and the mean rate of inflation are positively correlated because the variability of real shocks is the predominant cause of nominal uncertainty. In particular, more variable shocks cause a reduction in the degree of indexation and increase the benefits of creating surprise inflation to the government.

\subsection{The impact of output growth and inflation on the uncertainty about inflation and output growth}

The causal effects of inflation and output growth changes on nominal and real uncertainty can be examined according to the theories outlined in sections 2.1-2.3 above. Friedman (1977) argues that during high-inflation periods it is more likely that the monetary authority will instigate an erratic policy response, and therefore, uncertainty about the future inflation rate increases (the so-called Friedman hypothesis). The informal argument presented by Friedman (1977) was subsequently formalized by Ball (1992), who analyses an asymmetric information game where the public faces uncertainty about the type of the policy-maker in office. Policy-makers alternate stochastically in office and can be of two types: a weak type unwilling to disinflate and a tough type prepared to bear the costs of disinflation. During periods of high inflation, uncertainty about the type of policy-maker who will be in office in the next period increases uncertainty about the rate of money growth and hence the future inflation rate. During periods of low inflation, such uncertainty does not arise. Similarly, Azariadis and Smith (1996), in a model of credit market imperfections that take the form of informational frictions, show that if inflation exceeds a threshold, it leads to higher nominal uncertainty. Opposite to the FriedmanBall hypothesis, Ungar and Zilberfarb (1993) show formally that as inflation increases, agents may invest more resources in forecasting inflation, thus curtailing nominal uncertainty. In summary, theoretically speaking, the effect of inflation on its uncertainty is ambiguous. Similarly, the effect of inflation on output uncertainty is ambiguous. In particular, a rising inflation rate would be expected to have a negative impact on real uncertainty via a combination of the Friedman and Taylor effects. However, this impact could be positive: higher inflation reduces its 
uncertainty (Ungar and Zilberfarb effect) and increases output uncertainty (Taylor hypothesis).

The sign of the effect of output growth on macroeconomic uncertainty is also ambiguous. Consider first the effect of higher real growth on nominal uncertainty. A higher growth rate will raise inflation according to the 'Phillips curve' effect and, therefore, inflation uncertainty, as predicted by the Friedman hypothesis. Hence, the impact of output growth on nominal uncertainty is positive. On the contrary, the increased inflation rate arising from more real growth might reduce rather than increase inflation uncertainty (Ungar and Zilberfarb hypothesis). In this case, the effect will be negative. Two more theories predict a negative effect. First, Brunner (1993) claims that a decline in economic activity generates uncertainty about the response of the monetary authority and hence the average rate of inflation. Secondly, if more output growth leads to less inflation because of the inflation-stabilizing actions of the monetary authority, inflation uncertainty also falls (Friedman hypothesis). Finally, consider now the effect of growth on real uncertainty. An increase in real growth, given that the 'Phillips curve' and Friedman effects hold, pushes nominal uncertainty upwards and output uncertainty downwards (Taylor effect). However, if the impact of inflation on its uncertainty is negative, the opposite conclusion applies.

\section{The empirical evidence}

Early empirical studies on the relationship between inflation nominal uncertainty and output uncertainty used either the dispersion of survey forecasts of inflation or the variance of the inflation rate as a measure of uncertainty. Several recent studies measured nominal uncertainty using the conditional variance of the inflation process. Holland (1993) and Davis and Kanago (2000) provide a good review of the studies using these three measures of uncertainty. In general, the majority of the studies measuring the variance of the inflation rate and the dispersion of inflation forecasts find evidence supporting the first part of the Friedman hypothesis, i.e. more inflation leads to more inflation uncertainty. Similar evidence is obtained in more recent studies that use GARCH measures of inflation uncertainty, as in Grier and Perry (1998), Fountas (2001), Karanasos, Karanassou and Fountas (2004), and Conrad and Karanasos (2005). The second part of the Friedman hypothesis is examined in a number of studies using various measures of inflation variability and the dispersion of survey forecasts of inflation (see Holland, 1993). The majority of these studies find evidence in favour of the negative welfare effects of nominal uncertainty. GARCH studies supporting the hypothesis that inflation uncertainty has negative welfare effects are limited and only employ US data (e.g. Grier and Perry, 2000; Grier et al., 
2004; Elder, 2004). Fountas et al. (2004a), testing this hypothesis using data for six European countries, find mixed evidence.

The causal impact of inflation uncertainty on inflation is tested empirically using the GARCH approach, among others, in Baillie, Chung and Tieslau (1996), Grier and Perry (1998, 2000), and Hwang (2001). Most of these studies employ US data, the only exceptions being Baillie et al. (1996) and Grier and Perry (1998). In general, the evidence is mixed. Baillie et al. (1996) find evidence supporting the Cukierman-Meltzer hypothesis for the UK and some high-inflation countries, whereas Grier and Perry (1998) in their G7 study find evidence in favour of the Cukierman-Meltzer hypothesis for some countries and in favour of the Holland hypothesis for other countries. The studies by Grier et al. (2004) and Karanasos et al. (2004) employ US data and find evidence for a negative and positive effect of inflation uncertainty on inflation respectively.

The early empirical literature on the association between output variability and growth employed cross-sectional and pooled data and obtained mixed results (see Kneller and Young, 2001, for a review). Empirical evidence on the causal effect of real uncertainty (measured by the conditional variance of shocks to the output series) on growth has appeared only recently. Caporale and McKiernan (1996, 1998) obtain evidence of a positive causal effect using UK and US data, respectively, supporting, among others, the Black hypothesis. Speight (1999) finds no relationship between real uncertainty and growth and Henry and Olekalns (2002) find evidence of a negative effect. Grier and Perry (2000) and Grier et al. (2004) find US evidence of a positive effect. Fountas et al. (2002) and Fountas, Karanasos and Mendoza (2004b) find no evidence of a significant effect in Japan. No evidence exists, to the best of our knowledge, on the opposite type of causality, i.e. from output growth to its uncertainty.

Despite the numerous studies on the impact of growth on the inflation rate, there still exists some controversy over the robustness of this effect. A study by Kearney and Chowdhury (1997) involving 70 countries for the period 1960-89 finds no causal relationship between inflation and economic growth in $40 \%$ of the countries. They report bidirectional causality in about $20 \%$ of countries and a unidirectional (either inflation to growth or vice versa) relationship in the rest. More interestingly, the relationship is found to be positive in some cases, but negative in others. In a recent study, Mallik and Chowdhury (2001) examine the relationship between growth and inflation in four South Asian countries and find that growth has a significant positive (short-run) impact on inflation.

Haslag (1997) and Klump (2003) survey the empirical literature examining the relationship between movements in the inflation rate and output growth. Although a few studies have found no relationship between inflation and the 
growth rate, the general consensus is that growth is significantly and negatively related to inflation. ${ }^{4}$ In other words, over the last 20 years, the contours of an inverse connection between inflation and growth across countries have begun to emerge from econometric studies. Some of these studies are summarized in Gylfason and Herbertsson (2001). Bruno and Easterly (1996) suggest that the power of growth-inflation relationships in the empirical long-run growth literature seems to be coming from the short-run rather than the long run. They find a negative short-run relationship between inflation and growth. Recent empirical studies suggest that, for industrial countries, the threshold level of inflation above which inflation significantly slows growth is estimated at $1-3 \%$ (Klump, 2003). This negative effect is strongly supported in Gillman, Harris and Matyas (2003). Although the empirical evidence can be regarded as suggestive, it is broadly consistent with the theoretical results. ${ }^{5}$

Finally, the empirical evidence on the rest of the testable hypotheses discussed above is limited. Grier and Perry (2000) and Grier et al. (2004) test for the Devereux hypothesis and find no supporting evidence. Logue and Sweeney (1981), using a cross-sectional approach, find that higher inflation variability leads to more output growth variability. Lee (1999) provides some weak evidence for the Taylor effect. Karanasos and Kim (2005) find that there is no causal relationship between nominal and real uncertainty in the G3 countries, Germany, Japan, and the US.

\section{A bivariate GARCH model of inflation and output growth}

We use a bivariate GARCH model to simultaneously estimate the conditional means, variances and covariances of inflation and output growth. Let $\pi_{t}$ and $y_{t}$ denote the inflation rate and real output growth, respectively, and define the residual vector $\varepsilon_{t}$ as $\varepsilon_{t}=\left(\varepsilon_{\pi t} \varepsilon_{y t}\right)^{\prime}$. Note that a general bivariate $\operatorname{VAR}(p)$ model can be written as

$$
x_{t}=\Phi_{0}+\sum_{i=1}^{p} \Phi_{i} x_{t-i}+\varepsilon_{t},
$$

with

\footnotetext{
${ }^{4}$ The apparent importance of a wide range of other factors makes it more difficult to gauge the significance and magnitude of the impact of inflation on growth. It seems altogether too vulnerable to bias from omitted variables and reverse causation. But at the broadest level, the available evidence supports the view that well-run and well-governed economies tend to exhibit both low inflation and high growth (Briault, 1995).

${ }^{5}$ There are a number of reasons to treat all the results with some caution. The results might be sensitive to the sample of countries used, the definitions of the variables and the specifications of the estimated equations. Despite a number of shortcomings, the available evidence provides support for a negative relationship between inflation and growth, consistent with the predictions of the theoretical literature (Briault, 1995). For a critical review of the emerging empirical literature on inflation and growth, see also Temple (2000).
} 


$$
\Phi_{0}=\left[\begin{array}{c}
\phi_{\pi 0} \\
\phi_{y 0}
\end{array}\right] \quad \text { and } \quad \Phi_{i}=\left[\begin{array}{cc}
\phi_{\pi \pi, i} & \phi_{\pi y, i} \\
\phi_{y \pi, i} & \phi_{y y, i}
\end{array}\right]
$$

where $x_{t}$ is a $2 \times 1$ column vector given by $x_{t}=\left(\pi_{t} y_{t}\right)^{\prime}, \Phi_{0}$ is the $2 \times 1$ vector of constants and $\Phi_{i}, i=1, \ldots, p$, is the $2 \times 2$ matrix of autoregressive parameters. In our empirical work, we estimate several bivariate vector autoregressive (VAR) specifications for inflation and output growth. We estimate VAR models of order up to 12. We use the optimal lag-length algorithm of the Akaike (AIC) and Schwarz (SIC) information criteria to determine the order of the VAR process. Regarding $\varepsilon_{t}$ we assume that it is conditionally normal with mean vector 0 and covariance matrix $H_{t}$. That is, $\left(\varepsilon_{t} \mid \Omega_{t-1}\right) \sim N\left(0, H_{t}\right)$, where $\Omega_{t-1}$ is the information set up to time $t-1$. We also estimate VAR models where the $\Phi_{i}$ matrix is either lower triangular $\left(\phi_{\pi y, i}=0\right)$, or upper triangular $\left(\phi_{y \pi, i}=0\right)$ or diagonal $\left(\phi_{y \pi, i}=\phi_{\pi y, i}=0\right)$. The best model is chosen on the basis of Granger-causality tests. ${ }^{6}$ Following Bollerslev (1990), we perform the Granger-causality tests by imposing the constant conditional correlation (ccc) $\operatorname{GARCH}(1,1)$ structure on the conditional covariance matrix $H_{t}$ :

$$
\begin{gathered}
h_{\pi t}=\omega_{\pi}+\beta_{\pi} h_{\pi, t-1}+a_{\pi} \varepsilon_{\pi, t-1}^{2}, \\
h_{y t}=\omega_{y}+\beta_{y} h_{y, t-1}+a_{y} \varepsilon_{y, t-1}^{2}, \\
h_{\pi y, t}=\rho \sqrt{h_{\pi t}} \sqrt{h_{y t}}
\end{gathered}
$$

where $h_{\pi t}$ and $h_{y t}$ denote the conditional variances of the inflation rate and output growth, respectively, and $h_{\pi y, t}$ is the conditional covariance between $\varepsilon_{\pi t}$ and $\varepsilon_{y t}$. It is assumed that $\omega_{i}, a_{i}>0, \beta_{i} \geq 0$, for $i=\pi, y$, and $-1 \leq \rho \leq 1$. $^{7}$

We measure inflation and output uncertainty by their respective estimated conditional variances. Depending on model specification, causation in mean

${ }^{6}$ In the presence of conditional heteroskedasticity, Vilasuso (2001) investigates the reliability of causality tests based on least squares. He demonstrates that when conditional heteroskedasticity is ignored, least squares causality tests exhibit considerable size distortion if the conditional variances are correlated. In addition, inference based on a heteroskedasticity and autocorrelation consistent covariance matrix constructed under the least squares framework offers only slight improvement. Therefore, he suggests that causality tests be carried out in the context of an empirical specification that models both the conditional means and conditional variances.

${ }^{7}$ For the USA, we also estimate our bivariate $\operatorname{GARCH}(1,1)$ system using two alternative models of the conditional covariance matrix, first, the matrix-diagonal (MD) model introduced by Bollerslev, Engle and Nelson (1994) and, second, following Engle and Kroner (1995), we assume that the conditional covariance matrix follows the Baba, Engle, Kroner and Kraft (BEKK) representation. 
can exist with or without the presence of causality in variance and vice versa (Cheung and $\mathrm{Ng}$, 1996). This observation motivates us to use Grangercausality tests (the two-step approach) to investigate whether there exists causation in both the mean and the variance. The causality tests between inflation and output growth are performed in a bivariate framework, i.e. the VAR-GARCH model specified by equations (1) and (2) above. These tests also allow us to specify the form of the $\Phi_{i}$ matrix. The causality tests involving the conditional variances are performed in a four-variate framework.

To test for the causal relationships among inflation, growth, inflation uncertainty and growth uncertainty, one can use an alternative approach, the so-called simultaneous approach. Under this methodology, a bivariate GARCH-in-mean model is estimated where each conditional variance equation incorporates the lagged values of both the inflation rate and the real growth rate also. However, we prefer the two-step approach for the following reasons (see Grier and Perry, 1998). (1) The simultaneous approach does not allow us to capture the lagged causal effects of the conditional variances on the conditional means. (2) The incorporation of the lagged conditional mean in the conditional variance equation may lead to the negativity of the conditional variance. (3) The Granger causality approach minimizes the number of estimated parameters. (4) The Baba, Engle, Kroner and Kraft (BEKK) model is not useful in testing for causality in variances because it restricts the effect to being positive.

\section{Empirical results}

\subsection{Data and empirical approach}

We use monthly data for the G7 on a price index (PI) and the industrial production index (IPI) as measures of the price level and output respectively. Table 1 summarizes the data definition and sample size for all countries. $^{8}$ Inflation is measured by the annualized monthly difference of the $\log \mathrm{PI}\left[\pi_{t}=\log \left(\mathrm{PI}_{t} / \mathrm{PI}_{t-1}\right) \times 1200\right]$. Real output growth is measured by the annualized monthly difference in the log of the IPI $\left[y_{t}=\log \left(\operatorname{IPI}_{t} / \operatorname{IPI}_{t-1}\right) \times\right.$ 1200].

To test for a unit root in our data, we apply augmented Dickey-Fuller (ADF) and Phillips-Perron (PP) tests to both the inflation and output growth rates. The results of these tests are reported in Table 2 . Both tests reject the null hypothesis of a unit root at the 0.01 significance level implying that we can treat the inflation rate and the growth rate of industrial production as

\footnotetext{
${ }^{8}$ As the starting date of the wholesale price index (WPI) for France and Italy is much later than 1961; for these two countries, we measure prices by the consumer price index (CPI).
} 
TABLE 1

Price and output data for 67 countries

\begin{tabular}{lllll}
\hline Country $^{\mathrm{a}}$ & $\begin{array}{l}\text { Price } \\
\text { data }^{\mathrm{b}}\end{array}$ & $\begin{array}{l}\text { Output } \\
\text { data }\end{array}$ & Sample period & $\begin{array}{l}\text { Number of } \\
\text { observations }\end{array}$ \\
\hline US & WPI & IPI & $1957: 02-2000: 08$ & 523 \\
UK & IOP & IPI & $1957: 02-2000: 07$ & 522 \\
GER & PPI & IPI & $1958: 02-2000: 07$ & 510 \\
FRA & CPI & IPI & $1961: 02-2000: 06$ & 473 \\
ITA & CPI & IPI & $1961: 02-2000: 05$ & 472 \\
CAN & AISP & IPI & $1957: 02-2000: 07$ & 522 \\
JAP & WPI & IPI & $1957: 02-2000: 08$ & 523 \\
\hline
\end{tabular}

Notes: The price data for France and Italy were obtained from the OECD Main Indicators. The rest of the data were obtained from the International Financial Statistics (IFS).

${ }^{a}$ US: United States, UK: United Kingdom, GER: Germany, FRA: France, ITA: Italy, CAN: Canada, JAP: Japan.

${ }^{b}$ IOP: Industrial output price, PPI : producer price index, AISP: aggregate industrial selling price.

TABLE 2

Unit-root tests

\begin{tabular}{llllllll}
\hline \multicolumn{1}{c}{$U S$} & UK & GER & FRA & \multicolumn{1}{l}{ ITA } & \multicolumn{1}{l}{ CAN } & \multicolumn{1}{l}{ JAP } \\
\hline Inflation & & & & & & & \\
ADF & -6.33 & -7.44 & -6.01 & -3.79 & -3.86 & -5.29 & -5.52 \\
PP & -17.05 & -21.92 & -14.22 & -9.73 & -8.20 & -16.20 & -9.05 \\
Output growth & & & & & & \\
ADF & -9.00 & -10.68 & -10.43 & -12.77 & -10.72 & -8.03 & -6.28 \\
PP & -14.84 & -27.92 & -38.58 & -31.71 & -32.41 & -27.32 & -26.31 \\
\hline
\end{tabular}

Notes: A constant and four-lagged differenced terms are used for the augmented Dickey-Fuller test. The MacKinnon critical value for the rejection of the unit root null hypothesis at the $1 \%$ significance level is -3.45 .

stationary processes in all countries. ${ }^{9}$ We estimate the relationship between the inflation rate and output growth using the bivariate $\operatorname{VAR}(p)$ model presented in equation (1), where $p=12$. We assume that the conditional covariance matrix $H_{t}$ follows the ccc GARCH(1,1) model defined in equation (2). We also assume that $\varepsilon_{t}$ is conditionally normal. ${ }^{10}$ Table 3 reports estimates of the bivariate model for the US. To decide on the form of the $\Phi_{i}$ matrix, we first perform bivariate Granger causality tests between inflation and output.

\footnotetext{
${ }^{9}$ Note that the results from the ADF tests are not sensitive to the number of lagged differenced terms. Likewise, the results from the PP tests are not sensitive to the choice of truncation lag.

${ }^{10}$ For completeness, we have also estimated our bivariate $\operatorname{VAR}(12)$-ccc $\operatorname{GARCH}(1,1)$ models assuming conditionally $t$-distributed errors. Results from these models (not reported) are quite similar to those reported in the text using the normal distribution.
} 
TABLE 3

Bivariate AR(12)-constant conditional correlation GARCH(1,1) Model (US)

Inflation equations

(1) $\pi_{t}=\underset{(2.11)}{0.593}+\underset{(5.28)}{0.282} \pi_{t-1}+\underset{(0.80)}{0.042} \pi_{t-2}+\underset{(1.24)}{0.072} \pi_{t-3}-\underset{(1.21)}{0.054} \pi_{t-4}+\underset{(0.79)}{0.04} \pi_{t-5}$

$+\underset{(3.05)}{0.153} \pi_{t-6}-\underset{(1.45)}{0.071} \pi_{t-7}+\underset{(1.78)}{0.082} \pi_{t-8}+\underset{(0.98)}{0.046} \pi_{t-9}+\underset{(1.47)}{0.070} \pi_{t-10}$

$+\underset{(0.39)}{0.018} \pi_{t-11}+\underset{(2.40)}{0.111} \pi_{t-12}+\varepsilon_{\pi t}$

(2) $h_{\pi t}=\underset{(3.08)}{2.35}+\underset{(5.92)}{0.217} \varepsilon_{\pi, t-1}^{2}+\underset{(16.91)}{0.723} h_{\pi, t-1}$

Output growth equations

(3) $y_{t}=\underset{(4.84)}{2.98}+\underset{(3.56)}{0.211} y_{t-1}+\underset{(1.29)}{0.081} y_{t-2}+\underset{(1.85)}{0.103} y_{t-3}+\underset{(0.55)}{0.033} y_{t-4}-\underset{(0.48)}{0.028} y_{t-5}$

$-\underset{(0.86)}{0.044} y_{t-6}+\underset{(0.58)}{0.031} y_{t-7}+\underset{(0.93)}{0.045} y_{t-8}+\underset{(0.56)}{0.025} y_{t-9}+\underset{(0.65)}{0.035} y_{t-10}$

$-\underset{(0.23)}{0.01} y_{t-11}-\underset{(1.46)}{0.062} y_{t-12}+\underset{(1.21)}{0.075} \pi_{t-1}-\underset{(0.04)}{0.002} \pi_{t-2}-\underset{(0.55)}{0.028} \pi_{t-3}$

$-\underset{(2.08)}{0.102} \pi_{t-4}-\underset{(0.33)}{0.017} \pi_{t-5}-\underset{(1.04)}{0.078} \pi_{t-6}-\underset{(0.30)}{0.024} \pi_{t-7}-\underset{(0.02)}{0.001} \pi_{t-8}$

$+\underset{(0.91)}{0.053} \pi_{t-9}-\underset{(1.59)}{0.098} \pi_{t-10}-\underset{(0.43)}{0.031} \pi_{t-11}+\underset{(0.20)}{0.013} \pi_{t-12}+\varepsilon_{y t}$

(4) $h_{y t}=\underset{(3.33)}{6.22}+\underset{(4.67)}{0.169} \varepsilon_{y, t-1}^{2}+\underset{(17.50)}{0.77} h_{y, t-1}$

Constant conditional correlation

(5) $h_{\pi y, t}=\underset{(0.21)}{0.011} \sqrt{h_{\pi t}} \sqrt{h_{y t}}$

Notes: Table 3 reports parameter estimates of the bivariate $\operatorname{AR}(12)-\operatorname{ccc} \operatorname{GARCH}(1,1)$ model for the US data.

The numbers in parentheses are absolute $t$-statistics.

The results of these tests, reported in Table 7 , indicate that the $\Phi_{i}$ matrix is lower triangular. ${ }^{11}$

The estimated parameters of the conditional mean and variance equations for inflation are reported in equations (1) and (2) of Table 3. The sum of lagged inflation coefficients is 0.791 . The ARCH and GARCH parameters are significant at the 0.01 level. Equations (3) and (4) in Table 2 report estimates of the conditional mean and variance of output growth. The sum of lagged output coefficients is 0.42 . Both the GARCH and $\mathrm{ARCH}$ parameters are highly significant. The sum of the ARCH and GARCH parameters are 0.940 for both the inflation rate and output growth; i.e. for both series, current

\footnotetext{
${ }^{11}$ The VAR coefficients for the other countries are not reported but are available upon request. In particular, according to the Granger-causality test results reported in Table 7, the $\Phi_{i}$ matrix for the UK, France, Italy and Japan is lower triangular whereas for Canada it is upper triangular. Finally, for Germany, the full $\Phi_{i}$ matrix is used.
} 
TABLE 4

Constant conditional correlation GARCH(1,1) models

\begin{tabular}{|c|c|c|c|c|c|c|}
\hline & $U K$ & GER & $F R A$ & ITA & $C A N$ & $J A P$ \\
\hline \multicolumn{7}{|c|}{ Inflation equation } \\
\hline$\omega_{\pi}$ & $\begin{array}{c}11.730 \\
{[1.57]}\end{array}$ & $\begin{array}{l}2.823 \\
{[2.38]}\end{array}$ & $\begin{array}{c}1.205 \\
{[2.70]}\end{array}$ & $\begin{array}{c}0.073 \\
{[1.05]}\end{array}$ & $\begin{array}{l}1.020 \\
{[2.00]}\end{array}$ & $\begin{array}{c}11.590 \\
{[3.70]}\end{array}$ \\
\hline$a_{\pi}$ & $\begin{array}{l}0.106 \\
{[1.06]}\end{array}$ & $\begin{array}{l}0.168 \\
{[3.19]}\end{array}$ & $\begin{array}{c}0.121 \\
{[4.06]}\end{array}$ & $\begin{array}{l}0.107 \\
{[4.68]}\end{array}$ & $\begin{array}{l}0.105 \\
{[4.19]}\end{array}$ & $\begin{array}{c}0.223 \\
{[4.13]}\end{array}$ \\
\hline$\beta_{\pi}$ & $\begin{array}{c}0.797 \\
{[6.35]}\end{array}$ & $\begin{array}{c}0.597 \\
{[4.49]}\end{array}$ & $\begin{array}{l}0.731 \\
{[11.28]}\end{array}$ & $\begin{array}{l}0.890 \\
{[48.10]}\end{array}$ & $\begin{array}{l}0.865 \\
{[28.31]}\end{array}$ & $\begin{array}{c}0.376 \\
{[2.76]}\end{array}$ \\
\hline \multicolumn{7}{|c|}{ Output growth equation } \\
\hline$\omega_{y}$ & $\underset{[2.33]}{31.180}$ & $\begin{array}{c}54.750 \\
{[2.19]}\end{array}$ & $\begin{array}{c}73.580 \\
{[4.37]}\end{array}$ & $\underset{[3.64]}{221.600}$ & $\begin{array}{l}6.193 \\
{[1.62]}\end{array}$ & $\begin{array}{c}11.460 \\
{[1.40]}\end{array}$ \\
\hline$a_{y}$ & ${ }_{[4.31]}^{0.101}$ & $\begin{array}{l}0.057 \\
{[2.47]}\end{array}$ & $\begin{array}{c}0.489 \\
{[5.73]}\end{array}$ & $\begin{array}{l}0.177 \\
{[3.48]}\end{array}$ & $\begin{array}{l}0.068 \\
{[3.23]}\end{array}$ & $\begin{array}{l}0.056 \\
{[2.14]}\end{array}$ \\
\hline$\beta_{y}$ & $\begin{array}{l}0.797 \\
{[13.38]}\end{array}$ & $\begin{array}{l}0.800 \\
{[10.55]}\end{array}$ & $\begin{array}{c}0.336 \\
{[4.55]}\end{array}$ & $\begin{array}{c}0.497 \\
{[4.30]}\end{array}$ & $\begin{array}{l}0.903 \\
{[30.01]}\end{array}$ & $\begin{array}{l}0.895 \\
{[16.86]}\end{array}$ \\
\hline \multicolumn{7}{|c|}{ Constant conditional correlation } \\
\hline$\rho$ & $\begin{array}{l}0.169 \\
{[1.75]}\end{array}$ & $\begin{array}{c}0.060 \\
{[0.97]}\end{array}$ & $\begin{array}{c}0.063 \\
{[1.23]}\end{array}$ & $\begin{array}{c}0.020 \\
{[0.36]}\end{array}$ & $\begin{array}{l}0.008 \\
{[0.16]}\end{array}$ & $\begin{array}{c}0.025 \\
{[0.47]}\end{array}$ \\
\hline
\end{tabular}

Notes: Absolute $t$-statistics are given in brackets.

information remains important for the forecasts of the conditional variances for long horizons. Table 4 reports the estimated ARCH and GARCH parameters and the conditional correlations in the rest of the countries. The ccc is not statistically different from zero, suggesting that the residual covariance between equations is not statistically significant. We also calculate Ljung-Box $Q$ statistics at 12 lags for the levels, squares, and cross-equation products of the standardized residuals for the estimated bivariate GARCH system. The results, reported in Table 5, show that the time-series models for the conditional means and the ccc-GARCH $(1,1)$ model for the conditional (co)variances adequately capture the joint distribution of the disturbances.

Next, we perform Granger-causality tests to provide some statistical evidence on the nature of the relationship among average inflation, output growth, nominal uncertainty and real uncertainty. In performing the causality tests, we include all four variables in the equations, thus controlling for the effects of inflation uncertainty on output. Tables 6,7 and 8 provide the $F$-statistics of Granger-causality tests using four, eight and 12 lags, as well as the sign of the sums of the lagged coefficients in case of statistical significance.

\subsection{The impact of macroeconomic uncertainty on inflation and output growth}

The Granger-causality test results of macroeconomic uncertainty on inflation and output growth are given in Table 6. Friedman's hypothesis regarding the 
TABLE 5

Residual diagnostics

\begin{tabular}{|c|c|c|c|c|c|c|c|}
\hline & $U S$ & $U K$ & GER & $F R A$ & ITA & $C A N$ & $J A P$ \\
\hline \multicolumn{8}{|c|}{ Inflation equation } \\
\hline$Q_{12}$ & 5.23 & 6.66 & 5.71 & 3.30 & 13.67 & 10.19 & 19.37 \\
\hline$Q_{12}^{2}$ & 11.42 & 0.30 & 8.23 & 18.30 & 8.97 & 21.00 & 14.21 \\
\hline \multicolumn{8}{|c|}{ Output growth equation } \\
\hline$Q_{12}$ & 4.00 & 1.37 & 0.42 & 9.59 & 3.97 & 1.11 & 4.55 \\
\hline$Q_{12}^{2}$ & 16.18 & 0.66 & 18.04 & 3.18 & 19.94 & 14.42 & 11.54 \\
\hline \multicolumn{8}{|c|}{ Cross equation } \\
\hline$Q_{12}$ & 18.58 & 0.06 & 6.59 & 11.11 & 9.93 & 11.94 & 5.23 \\
\hline
\end{tabular}

Notes: $Q_{12}$ is the 12th-order Ljung-Box test for standardized residuals.

$Q_{12}^{2}$ is the Ljung-Box test for squared standardized residuals. The critical value at $5 \%$ significance level is 21.02 .

TABLE 6

Bivariate Granger-causality tests from uncertainty about inflation and output growth to inflation and output growth

\begin{tabular}{|c|c|c|c|c|c|c|c|}
\hline & $U S$ & $U K$ & GER & $F R A$ & ITA & $C A N$ & $J A P$ \\
\hline \multicolumn{8}{|c|}{ Panel (A) $\mathrm{H}_{0}$ : Inflation uncertainty does not Granger-cause output growth } \\
\hline 4 lags & $4.50 * * *(-)$ & 0.65 & $2.61 * *(-)$ & 0.39 & 1.03 & 1.46 & $8.61 * * *(-)$ \\
\hline 8 lags & $\overline{2.45} * * *(-)$ & $\overline{2.56}^{* * *}(-)$ & 1.38 & $\overline{0.47}$ & $\overline{1.12}$ & $\overline{1.72} *(-)$ & $\overline{\mathbf{5 . 8 1}} * * *(-)$ \\
\hline 12 lags & $3.89 * * *(-)$ & $3.36 * * *(-)$ & $\overline{1.41} \dagger(-)$ & 0.58 & 1.28 & $2.05 * * *(-)$ & $3.95 * * *(-)$ \\
\hline \multicolumn{8}{|c|}{ Panel (B) $\mathrm{H}_{0}$ : Inflation uncertainty does not Granger-cause inflation } \\
\hline 4 lags & $4.58 * * *(+)$ & $12.40 * * *(+)$ & 0.98 & $2.55^{* *}(+)$ & $2.50 * *(+)$ & $3.93 * * *(+)$ & $\underline{32.10}^{* * *}(-)$ \\
\hline 8 lags & $\overline{3.60} * * *(+)$ & $5.70 * * *(+)$ & $\overline{1.16}$ & $\overline{2.10} * *(+)$ & $\overline{1.38}$ & $\overline{2.56} * * *(+)$ & $\overline{18.60} * * *(-)$ \\
\hline 12 lags & $1.63 * *(-)$ & $5.49 * * *(+)$ & 1.28 & 1.25 & 1.30 & $2.36 * * *(+)$ & $9.69 * * *(-)$ \\
\hline \multicolumn{8}{|c|}{ Panel (C) $\mathrm{H}_{0}$ : Output growth uncertainty does not Granger-cause output growth } \\
\hline 4 lags & $2.96 * *(+)$ & $8.20 * * *(+)$ & $2.40 * *(+)$ & $19.5^{* * *}(+)$ & 1.11 & $2.40 * *(+)$ & 0.59 \\
\hline 8 lags & $\overline{2.43} * *(+)$ & $\overline{4.61} * * *(+)$ & $14.7 * * *(+)$ & $\overline{10.9} 0 * * *(+)$ & $\overline{1.63}+(+)$ & $\overline{\mathbf{1 . 5 0}} \div(+)$ & $\overline{\mathbf{0 . 8 1}}$ \\
\hline 12 lags & $\mathbf{4 . 4 0 * * *}(+)$ & $10.52 * * *(+)$ & $\overline{\mathbf{3 6 . 6 0}} * * *(+)$ & $7.97 * * *(+)$ & $1.99 * *(+)$ & 1.28 & 0.88 \\
\hline \multicolumn{8}{|c|}{ Panel (D) $\mathrm{H}_{0}$ : Output growth uncertainty does not Granger-cause inflation } \\
\hline 4 lag & 0.98 & 0.55 & $4.35 * * *(-)$ & $6.08 * * *(+)$ & 1.22 & 0.69 & 0.42 \\
\hline 8 lags & $\overline{0.91}$ & $\overline{0.40}$ & $\overline{4.20} * * *(-)$ & $\overline{4.26} * * *(+)$ & $\overline{2.28} * *(+)$ & $\overline{1.69} *(-)$ & $\overline{0.44}$ \\
\hline 12 lags & 0.90 & 0.51 & $1.95 * *(+)$ & $3.60 * * *(-)$ & $2.07 * *(+)$ & $2.93 * * *(-)$ & 1.03 \\
\hline
\end{tabular}

Notes: The numbers in the first column give the lag structure. Figures are $F$-statistics.

A (+) (-) indicates that the sum of the lagged coefficients of the causing variable is (positive) (negative).

$* * *, * *, *$ and $\dagger$ denote significance at the $0.01,0.05,0.1$ and 0.15 levels, respectively.

The bold (underlined) numbers indicate the optimal lag length chosen by AIC (SIC).

negative growth effects of inflation uncertainty receives support in all countries, except France and Italy (panel A). The evidence is stronger in Canada, Japan, the UK and the US where it applies for the majority of the chosen lags, and weaker in Germany where it applies for only two of the 
TABLE 7

Bivariate Granger-causality tests between (i) inflation and output growth and (ii) nominal and real uncertainty

\begin{tabular}{|c|c|c|c|c|c|c|c|}
\hline & US & $U K$ & GER & FRA & ITA & $C A N$ & $J A P$ \\
\hline \multicolumn{8}{|c|}{ Panel (A) $\mathrm{H}_{0}$ : Output growth does not Granger-cause inflation } \\
\hline 4 lags & 0.27 & $4.48^{* * *}(+)$ & 0.27 & 1.31 & 0.11 & $1.94 *(+)$ & 0.61 \\
\hline 8 lags & $\overline{0.67}$ & $\overline{0.65}$ & $\overline{0.53}$ & $2.45 * *(+)$ & $\overline{0.29}$ & $\overline{1.64}+(+)$ & $\overline{0.48}$ \\
\hline 12 lags & 0.88 & 0.76 & $1.52 \dagger(+)$ & $\underline{1.23}$ & 1.26 & $1.54 \dagger(+)$ & 0.55 \\
\hline \multicolumn{8}{|c|}{ Panel (B) $\mathrm{H}_{0}$ : Inflation does not Granger-cause output growth } \\
\hline 4 lags & $2.56^{* *}(-)$ & $8.32 * * *(-)$ & 0.48 & 0.06 & $2.18 *(-)$ & 0.63 & $2.30 *(-)$ \\
\hline 8 lags & $1.74 *(-)$ & $5.77 * * *(-)$ & $\overline{1.53}+(-)$ & $2.03 *$ & $1.81 *(-)$ & $\overline{1.11}$ & $2.40 *(-)$ \\
\hline 12 lags & $1.59 *(-)$ & $5.16^{* * *}(-)$ & $1.72 *(-)$ & $\underline{1.19}$ & $1.45 \dagger(-)$ & 0.78 & $2.37 * * *(-)$ \\
\hline \multicolumn{8}{|c|}{ Panel $(\mathrm{C}) \mathrm{H}_{0}$ : Inflation uncertainty does not Granger-cause output growth uncertainty } \\
\hline 4 lags & 1.09 & 0.69 & 0.33 & 1.03 & 1.65 & 0.44 & $2.25 *(-)$ \\
\hline 8 lags & $\overline{1.29}$ & $\overline{0.77}$ & 1.33 & $\overline{\mathbf{0 . 5 7}}$ & $\overline{1.35}$ & $\overline{0.74}$ & $2.82 * * *(-)$ \\
\hline 12 lags & 1.26 & 0.50 & $\underline{1.63}^{*}(-)$ & 0.47 & 1.09 & 0.71 & $\overline{2.20} * * *(-)$ \\
\hline \multicolumn{8}{|c|}{ Panel (D) $\mathrm{H}_{0}$ : Output growth uncertainty does not Granger-cause inflation uncertainty } \\
\hline 4 lags & 0.78 & 1.14 & $\underline{\mathbf{2 . 9 2}}^{* *(+)}$ & $\underline{1.15}$ & $\underline{0.94}$ & $\underline{\mathbf{2 . 0 9}} *(-)$ & $\underline{0.38}$ \\
\hline 8 lags & 0.27 & $\overline{\mathbf{1 . 0 8}}$ & $\overline{1.71} *(+)$ & $\overline{0.64}$ & $\overline{0.95}$ & $\overline{1.61} \dagger(-)$ & $\overline{0.26}$ \\
\hline 12 lags & 0.32 & 0.95 & 0.77 & 1.12 & 0.87 & 0.86 & 0.18 \\
\hline
\end{tabular}

Notes: The numbers in the first column give the lag structure. Figures are $F$-statistics.

A (+) (-) indicates that the sum of the lagged coefficients of the causing variable is (positive) (negative).

$* * *, * *, *$ and $\dagger$ denote significance at the $0.01,0.05,0.1$ and 0.15 levels, respectively.

The bold (underlined) numbers indicate the optimal lag length chosen by AIC (SIC).

chosen lags. Panel B reports the results of the tests of the causal effect of inflation uncertainty on inflation. The strongest evidence in favour of the Cukierman-Meltzer hypothesis applies for Canada and the UK. For France and the US, the evidence is not as strong as it applies for lags four and eight only. Relatively weak evidence applies for Italy (four lags). Evidence in favour of the Holland hypothesis applies in Japan. Neither of the two theories is supported in Germany where inflation is independent of changes in inflation uncertainty. Hence, overall, the evidence on the effect of inflation uncertainty on inflation is mixed.

The results reported in panel $\mathrm{C}$ strongly support the Black hypothesis that uncertainty about real growth affects positively the rate of output growth in all countries, except Japan. The lack of any effect of output uncertainty on output growth in Japan squares with the proposition of independence between real variability and economic growth outlined in section II. Finally, panel D reports mixed evidence on the impact of output growth uncertainty on inflation. Evidence for Devereux's (1989) theory is provided for France, Italy, and Germany (12 lags). In three of the seven countries, namely Japan, the UK 
TABLE 8

Bivariate Granger-causality tests from inflation and output growth to uncertainty about inflation and output growth

\begin{tabular}{|c|c|c|c|c|c|c|c|}
\hline & $U S$ & $U K$ & GER & FRA & ITA & $C A N$ & $J A P$ \\
\hline \multicolumn{8}{|c|}{ Panel (A) $\mathrm{H}_{0}$ : Inflation does not Granger-cause inflation uncertainty } \\
\hline 4 lags & $1.75 \dagger(+)$ & $\underline{3.50}^{* * *}(-)$ & $\underline{1.83} \dagger(+)$ & $\underline{1.84} \dagger(+)$ & $\mathbf{6 . 3 8}^{* * *}(+)$ & $2.59 * *(+)$ & $\mathbf{8 . 4 2}^{* * *}(+)$ \\
\hline 8 lags & $\overline{1.32}$ & $\overline{\mathbf{2 . 0 6}} * *(-)$ & $\overline{1.71} *(+)$ & $\overline{1.09}$ & $\overline{3.58} * * *(+)$ & $\overline{1.69} *(+)$ & $\overline{4.81} * * *(+)$ \\
\hline 12 lags & $1.45 \dagger(+)$ & $1.45 \dagger(-)$ & $1.61 *(+)$ & $1.45 \dagger(+)$ & $1.90 * *(+)$ & 1.19 & $3.93 * * *(+)$ \\
\hline \multicolumn{8}{|c|}{ Panel (B) $\mathrm{H}_{0}$ : Inflation does not Granger-cause output growth uncertainty } \\
\hline 4 lags & 0.99 & $\underline{2.23}^{*}(-)$ & 0.47 & 0.82 & $1.68 \dagger(+)$ & 1.38 & 0.28 \\
\hline 8 lags & 0.93 & 1.22 & $1.77 *(-)$ & $\overline{0.64}$ & 1.08 & $\overline{1.38}$ & $\underline{1.94}^{* *}(+)$ \\
\hline 12 lags & $\mathbf{1 . 0 3}$ & 0.91 & $1.46 \dagger(-)$ & 0.45 & $1.73 *(+)$ & 1.08 & $\overline{1.74} *(+)$ \\
\hline
\end{tabular}

Panel $(C) \mathrm{H}_{0}$ : Output growth does not Granger-cause inflation uncertainty

\begin{tabular}{|c|c|c|c|c|c|c|c|}
\hline 4 lags & 0.29 & $1.86+(-)$ & $1.89 \dagger(-)$ & 1.13 & $2.34 *(+)$ & 0.20 & 0.60 \\
\hline 8 lags & $\overline{0.25}$ & $\overline{1.08}$ & $\overline{1.28}$ & $\overline{0.40}$ & $\overline{1.47}$ & $\overline{0.38}$ & $\overline{0.58}$ \\
\hline 12 lags & 0.53 & 0.89 & 1.22 & 0.64 & 0.98 & 0.64 & 0.46 \\
\hline
\end{tabular}

Panel (D) $\mathrm{H}_{0}$ : Output growth does not Granger-cause output growth uncertainty

\begin{tabular}{llllllll} 
4 lags & $3.90^{* * *}(-)$ & $\mathbf{1 . 1 5}$ & $6.08^{* * *(+)}$ & $\frac{1.60}{\mathbf{0 . 6 9}}$ & $\underline{\mathbf{1 . 0 7}}$ & 0.14 \\
8 lags & $2.38^{* *(-)}$ & 0.59 & & $5.40^{* * *(-)}$ & $\mathbf{1 . 2 1}$ & $\frac{1.03}{1.42}$ & $\underline{\mathbf{1 . 5 3}}^{\dagger(-)}$ \\
12 lags & $\mathbf{1 . 2 8}$ & 0.52 & $\underline{\mathbf{1 . 7 2}}^{*}(-)$ & 0.81 & 0.94 & 0.99 & $2.35^{* * *(-)}$ \\
\hline
\end{tabular}

Notes: The numbers in the first column give the lag structure. Figures are $F$-statistics.

A (+) (-) indicates that the sum of the lagged coefficients of the causing variable is (positive) (negative).

$* * *, * *, *$ and $\dagger$ denote significance at the $0.01,0.05,0.1$ and 0.15 levels, respectively.

The bold (underlined) numbers indicate the optimal lag length chosen by AIC (SIC).

and the US, we find no effect of output uncertainty on inflation. This lack of a direct effect is in agreement with the absence of an indirect effect that takes place via changes in inflation uncertainty. ${ }^{12}$ Finally, in Canada there is evidence of a negative impact which squares with the Taylor effect and the Cukierman-Meltzer hypothesis.

\subsection{The relationship between inflation and output growth}

The Granger-causality tests between inflation and output growth are performed in a bivariate setting using the VAR-GARCH model of equations (1) and (2). ${ }^{13}$ The results are reported in Table 7 . Regarding the impact of growth on inflation, panel A shows lack of such an effect in Italy, Japan and the US. In three countries, France, Germany and the UK, there is weak evidence in favour of a 'Phillips curve' effect, whereas in Canada the evidence

\footnotetext{
${ }^{12}$ Note that in these three countries, output growth uncertainty does not affect inflation uncertainty (see Table 7).

${ }^{13}$ These tests have been repeated using a four-variate system, the results being qualitatively similar.
} 
is stronger. The results in panel B indicate strong evidence in favour of the Klump hypothesis that higher inflation has a negative (direct) impact on growth in several countries. However, relatively weak evidence for a negative effect applies for France, Germany and Italy. For Japan, Germany and the US, this finding of a negative direct effect squares with an indirect impact: as Tables 6 and 8 indicate, inflation affects its uncertainty positively (the first part of the Friedman hypothesis) and nominal uncertainty affects real growth negatively (the second part of the Friedman hypothesis). Finally, for Canada, we find that inflation has no real effects.

\subsection{The relationship between inflation uncertainty and output uncertainty}

Table 7 also reports the results on the Granger-causality tests between uncertainty about inflation and economic growth. We find support for the Taylor effect only in Japan (see panel C). For all other countries, nominal uncertainty does not Granger-cause real uncertainty, except in Germany for which we find some weak evidence of the Taylor effect. The reverse type of causality (from output uncertainty to inflation uncertainty) exists in two of the seven countries, namely Canada and Germany (see panel D). The Taylor effect is supported by the Canadian data whereas the Devereux hypothesis is supported by the German data.

\subsection{The effects of output growth and inflation on macroeconomic uncertainty}

We report the Granger-causality test results (the values of the $F$-statistics) on the impact of changes in inflation and output growth on macroeconomic uncertainty in Table 8. Our results are as follows. According to the results of panel A, inflation affects its uncertainty positively as predicted by Friedman (1977) and Ball (1992) in most countries. The evidence is strong in Canada, Italy and Japan, and weaker in France, Germany and the US. In the UK, Ungar and Zilberfarb's (1993) view that inflation reduces its uncertainty finds strong support.

The results of panel $\mathrm{B}$ show that inflation has a mixed impact on real uncertainty. The impact is weakly positive in Italy and Japan, weakly negative in Germany and the UK, and zero in the rest of the countries. Recall that, theoretically speaking, the effect of inflation on the uncertainty about economic growth is ambiguous and is based on the interaction of the Friedman (or Ungar and Zilberfarb) hypothesis and the Taylor (or LogueSweeney) effect. Therefore, the absence of evidence for the Taylor effect in Canada, France, the US and the UK, as reported in section 5.4 is consistent with the absence of any effect from inflation on output uncertainty in the first three countries and the very weak effect in the last country. In other words, the 
lack of a direct effect of inflation on output uncertainty is in line with the lack of an indirect effect that works through the nominal uncertainty channel. In contrast, in Germany, the evidence for the Friedman and Taylor effects confirms the negative impact of inflation on output uncertainty, i.e. direct and indirect effects point to the same conclusion. Finally, in Japan, the evidence obtained for the Friedman and Taylor effects points towards a negative indirect impact whereas the direct effect is positive. Hence, some other mechanism (or theoretical explanation) must be at work to explain such a direct effect.

Panel C reports the results of the causal effects of output growth on inflation uncertainty. Overall, economic growth has a rather weak or zero impact on nominal uncertainty. The impact is weakly negative in Germany and the UK, and weakly positive in Italy. In the rest of the countries, the effect is zero. This result is, in general, consistent with the theoretical underpinnings that predict an ambiguous relationship between the two variables because of the interaction of the 'Phillips curve' effect with either the Friedman hypothesis or the Ungar and Zilberfarb effect. The negative impact of real growth on nominal uncertainty for the UK agrees with the evidence on the 'Phillips curve' effect and the Ungar and Zilberfarb hypothesis. The very weak evidence in Italy, and the lack of an effect in Japan and the US are consistent with the lack of an inflationary impact of output growth. The lack of evidence in France is consistent with the very weak evidence on the 'Phillips curve' effect and the Friedman hypothesis (Table 8, panel A). The very weak evidence of an effect in Germany is consistent with the very weak evidence of a 'Phillips curve' effect (Table 7, panel A).

Finally, panel D reports the results of the causal effects of output growth on its uncertainty. Economic growth has a negative effect on real uncertainty in Japan, the US and Germany (lags 8 and 12, only) and a zero effect in the rest of the countries. Theoretically speaking, the impact of growth on its uncertainty depends on the interaction of three effects: The 'Phillips curve', the Friedman (or Ungar and Zilberfarb), and the Taylor (or Logue-Sweeney) effects. The negative impact in Germany is consistent with the evidence for the 'Phillips curve', the Friedman and the Taylor effects. For Japan and US, some other mechanism must be at work to explain the negative impact of output growth on its uncertainty. Finally, the lack of a significant effect in Canada, France, Italy and the UK squares with the lack of an effect of inflation uncertainty on real uncertainty in these countries (see Table 7, panel C). ${ }^{14}$

\footnotetext{
${ }^{14}$ As mentioned earlier, for the US we have estimated two additional multivariate GARCH models that are alternative to the ccc model, namely the BEKK and MD models. The results (not reported) in most cases are qualitatively similar to those reported in Tables 6-8.
} 


\subsection{Discussion}

We obtain noteworthy results regarding the effect of macroeconomic uncertainty on inflation and output growth. First, we provide evidence that nominal uncertainty is detrimental to the growth prospects of most countries in our sample. Moreover, our results indicate that a higher rate of average inflation has a negative effect on growth in nearly all the G7. In other words, inflation tends to exert an adverse impact on real growth both directly and indirectly (via changes in nominal uncertainty). Our results are in line with the findings of empirical studies (based on the GARCH approach) predicting that inflation uncertainty is a negative determinant of growth. These studies are, with a few exceptions, limited to US data (Grier and Perry, 2000; Grier et al., 2004; Elder, 2004).

Regarding the causal effect of nominal uncertainty on average inflation, our evidence is country-specific. This is rather expected given that national central banks adjust their monetary growth rates differently to nominal uncertainty depending on their relative preferences towards inflation and output stabilization. More independent central banks would be identified with a stronger anti-inflation preference than a government and their monetary policy choice would accordingly result in a lower optimal inflation rate. Furthermore, if, first, nominal uncertainty affects economic growth negatively and second, inflation raises its uncertainty, an independent central bank will have a greater incentive (and freedom) to respond to rising uncertainty by reducing inflation. This is because in doing so the central bank can attain both lower inflation and higher growth. The predictions of this analysis are borne out by Alesina and Summers (1993), who show that more independent central banks are indeed associated with both lower inflation and nominal uncertainty.

Our results on the impact of nominal uncertainty on inflation are in general consistent with existing rankings of central bank independence (see Alesina and Summers, 1993 for a summary of such indices). For example, for Canada, France, Italy and the UK - countries with less independent central banks according to those rankings - we do find evidence consistent with the Cukierman-Meltzer hypothesis. In contrast, for the US (for the optimal lag length), a country with a high degree of central bank independence, we find evidence consistent with Holland's (1995) 'stabilizing Fed hypothesis'. It should be kept in mind, though, that central bank independence indices have been constructed on the basis of time periods different from our sample period and the degree of central bank independence has evolved significantly over the last 15 years.

We now turn to the effects of real uncertainty on growth. In six of the G7 we find that real uncertainty is a positive determinant to growth, thus supporting the Black (1987) and Blackburn (1999) hypotheses. The available 
evidence on this hypothesis is limited to US and UK data (Caporale and McKiernan, 1996, 1998; Grier and Perry, 2000; Grier et al., 2004). Our present findings are in line with most of the existing evidence.

\section{Conclusion}

We use monthly data on inflation and output growth on the G7 to examine the relationship among macroeconomic (nominal and real) uncertainty and macroeconomic performance, measured by the average inflation rate and the average rate of economic growth. The motivation for such an undertaking comes from the observed cross-country significant reduction in macroeconomic uncertainty and the improvement in macroeconomic performance in the last 20 years. Using the GARCH methodology to measure uncertainty, we derive several important conclusions for the majority of the countries in our sample. First, inflation is a negative determinant of real growth. This effect takes place both directly and indirectly, via the nominal uncertainty channel, as put forward by Friedman (1977). This finding supports the view that inflation does have real effects and justifies the goal of a low inflation rate for monetary policy-making. Our second conclusion is that in some countries, notably, Canada and the UK, and probably in France and Italy, central banks do tend to cause inflation surprises in the presence of more inflation uncertainty, as shown by Cukierman and Meltzer (1986). However, in Japan and the US (optimal lag length), the opposite holds. Thirdly, real uncertainty is a positive determinant of the rate of output growth, offering support to the theoretical arguments of Black (1987) and Blackburn (1999). This result has important implications for the construction of macroeconomic models and for policy-making. First, it implies that macro theorists who have treated, in general, the analysis of business cycle variability and the growth rate of the economy independently from each other, should consider the two simultaneously in their macroeconomic modelling. Secondly, the popular claim among the Organization for Economic Co-operation and Development (OECD) economies that increased stabilization of the business cycle is a requirement for long-run growth does not appear to find support in this study.

Final Manuscript Received: July 2005

\section{References}

Alesina, A. and Summers, L. (1993). 'Central bank independence and macroeconomic performance', Journal of Money, Credit, and Banking, Vol. 25, pp. 151-162.

Azariadis, C. and Smith, B. (1996). 'Private information, money, and growth: indeterminacies, fluctuations and the Mundell-Tobin effect', Journal of Economic Growth, Vol. 1, pp. 309-322. 
Baillie, R., Chung, C. and Tieslau, M. (1996). 'Analyzing inflation by the fractionally integrated ARFIMA-GARCH model', Journal of Applied Econometrics, Vol. 11, pp. 23-40.

Ball, L. (1992). 'Why does high inflation raise inflation uncertainty?', Journal of Monetary Economics, Vol. 29, pp. 371-388.

Black, F. (1987). Business Cycles and Equilibrium, Basil Blackwell, New York.

Blackburn, K. (1999). 'Can stabilisation policy reduce long-run growth?', Economic Journal, Vol. 109, pp. 67-77.

Blackburn, K. and Pelloni, A. (2004). 'On the relationship between growth and volatility', Economics Letters, Vol. 83, pp. 123-127.

Blackburn, K. and Pelloni, A. (2005). 'Growth, cycles and stabilisation policy', Oxford Economic Papers, Vol. 57, pp. 262-282.

Bollerslev, T. (1990). 'Modelling the coherence in short-run nominal exchange rates: a multivariate generalized ARCH approach', Review of Economics and Statistics, Vol. 72, pp. 498-505.

Bollerslev, T., Engle, R. and Nelson, D. (1994). 'ARCH models', in Engle R. and McFadden D. (eds), Handbook of Econometrics, Vol. IV, North Holland, Amsterdam, pp. 2959-3038.

Briault, C. (1995). 'The costs of inflation', Bank of England Quarterly Bulletin, February, pp. 33-45.

Brunner, A. (1993). 'Comment on inflation regimes and the sources of inflation uncertainty', Journal of Money, Credit, and Banking, Vol. 25, pp. 512-514.

Bruno, M. and Easterly, W. (1996). 'Inflation and growth: in search of a stable relationship', Review, Federal Reserve Bank of St. Louis, May/June, pp. 139-146.

Caporale, T. and McKiernan, B. (1996). 'The relationship between output variability and growth: evidence from post war UK data', Scottish Journal of Political Economy, Vol. 43, pp. 229-236.

Caporale, T. and McKiernan, B. (1998). 'The Fischer Black hypothesis: some time-series evidence', Southern Economic Journal, Vol. 64, pp. 765-771.

Cecchetti, S. and Ehrmann, M. (1999). Does Inflation Targeting Increase Output Volatility? An International Comparison of Policymakers' Preference and Outcomes, NBER Working Paper No. 7426.

Cecchetti, S. and Krause, S. (2001). Financial Structure, Macroeconomic Stability and Monetary Policy, NBER Working Paper No. 8354.

Cheung, Y.-W. and Ng, L. (1996). 'A causality-in-variance test and its application to financial market prices', Journal of Econometrics, Vol. 72, pp. 33-48.

Clarida, R., Gali, J. and Gertler, M. (1999). 'The science of monetary policy: a new Keynesian perspective', Journal of Economic Literature, Vol. XXXVII, pp. 1661-1707.

Conrad, C. and Karanasos, M. (2005). 'On the inflation-uncertainty hypothesis in the USA, Japan and the UK: a dual long-memory approach', Japan and the World Economy, Vol. 17, pp. 327-343.

Cukierman, A. and Gerlach, S. (2003). 'The inflation bias revisited: theory and some international evidence', The Manchester School, Vol. 71, pp. 541-565.

Cukierman, A. and Meltzer, A. (1986). 'A theory of ambiguity, credibility, and inflation under discretion and asymmetric information', Econometrica, Vol. 54, pp. 1099-1128.

Davis, G. and Kanago, B. (2000). 'The level and uncertainty of inflation: results from OECD forecasts', Economic Inquiry, Vol. 38, pp. 58-72.

Devereux, M. (1989). 'A positive theory of inflation and inflation variance', Economic Inquiry, Vol. 27, pp. 105-116.

Dotsey, M. and Sarte, P. (2000). 'Inflation uncertainty and growth in a cash-in-advance economy', Journal of Monetary Economics, Vol. 45, pp. 631-655. 
Elder, J. (2004). 'Another perspective on the effects of inflation uncertainty', Journal of Money, Credit and Banking, Vol. 36, pp. 911-928.

Engle, R. and Kroner, K. (1995). 'Multivariate simultaneous generalized ARCH', Econometric Theory, Vol. 11, pp. 122-150.

Fountas, S. (2001). 'The relationship between inflation and inflation uncertainty in the UK: 1885-1998', Economics Letters, Vol. 74, pp. 77-83.

Fountas, S. and Karanasos, M. (2006). 'Inflation, output growth, and nominal and real uncertainty: empirical evidence for the G7', Journal of International Money and Finance, forthcoming.

Fountas, S., Karanasos, M. and Kim, J. (2002). 'Inflation and output growth uncertainty and their relationship with inflation and output growth', Economics Letters, Vol. 75, pp. 293-301.

Fountas, S., Ioannidis, A. and Karanasos, M. (2004a). 'Inflation, inflation uncertainty, and a common European monetary policy', The Manchester School, Vol. 72, pp. 221-242.

Fountas, S., Karanasos, M. and Mendoza, A. (2004b). 'Output variability and economic growth: the Japanese case', Bulletin of Economic Research, Vol. 56, pp. 353-363.

Friedman, M. (1977). 'Nobel lecture: inflation and unemployment', Journal of Political Economy, Vol. 85, pp. 451-472.

Fuhrer, J. (1997). 'Inflation/output variance trade-offs and optimal monetary policy', Journal of Money, Credit, and Banking, Vol. 29, pp. 214-234.

Gillman, M. and Kejak, M. (2005). 'Contrasting models of the effect of inflation on growth', Journal of Economic Surveys, Vol. 1, pp. 113-136.

Gillman, M., Harris, M. and Matyas, L. (2003). 'Inflation and growth: explaining a negative effect', Empirical Economics, Vol. 1, pp. 149-167.

Goel, R. and Ram, R. (2001). 'Irreversibility of R\&D investment and the adverse effect of uncertainty: evidence from OECD countries', Economics Letters, Vol. 71, pp. 287-291.

Grier, K. and Perry, M. (1998). 'On inflation and inflation uncertainty in the G7 countries', Journal of International Money and Finance, Vol. 17, pp. 671-689.

Grier, K. and Perry, M. (2000). 'The effects of real and nominal uncertainty on inflation and output growth: some GARCH-M evidence', Journal of Applied Econometrics, Vol. 15, pp. 45-58.

Grier, K., Henry, O. T., Olekalns, N. and Shields, K. (2004). 'The asymmetric effects of uncertainty on inflation and output growth', Journal of Applied Econometrics, Vol. 19, pp. 551-565.

Gylfason, T. and Herbertsson, T. (2001). 'Does inflation matter for growth?', Japan and the World Economy, Vol. 13, pp. 405-428.

Haslag, J. H. (1997). 'Output, growth, welfare, and inflation: a survey', Economic Review, Federal Reserve Bank of Dallas, Second Quarter, pp. 11-21.

Henry, O. and Olekalns, N. (2002). 'The effect of recessions on the relationship between output variability and growth', Southern Economic Journal, Vol. 68, pp. 683-692.

Holland, S. (1993). 'Comment on inflation regimes and the sources of inflation uncertainty', Journal of Money, Credit, and Banking, Vol. 25, pp. 514-520.

Holland, S. (1995). 'Inflation and uncertainty: tests for temporal ordering', Journal of Money, Credit, and Banking, Vol. 27, pp. 827-837.

Hwang, Y. (2001). 'Relationship between inflation rate and inflation uncertainty', Economics Letters, Vol. 73, pp. 179-186.

Karanasos, M. and Kim, J. (2005). 'The inflation-output variability relationship in the G3: a bivariate GARCH (BEKK) approach', Risk Letters, Vol. 1, pp. 17-22.

Karanasos, M., Karanassou, M. and Fountas, S. (2004). 'Analyzing US inflation by a GARCH model with simultaneous feedback', WSEAS Transactions on Information Science and Applications, Vol. 1, pp. 767-772. 
Kearney, P. S. C. and Chowdhury, K. (1997). 'Inflation and economic growth: a multi-country empirical analysis', Applied Economics, Vol. 29, pp. 1387-1401.

Klump, R. (2003). Inflation, Factor Substitution and Growth, European Central Bank, Working Paper No. 280.

Kneller, R. and Young, G. (2001). 'Business cycle volatility, uncertainty and long-run growth', The Manchester School, Vol. 69, pp. 534-552.

Krause, S. (2003). Measuring Monetary Policy Efficiency in European Union Countries, Department of Economics, Emory University, Working Paper No. 03-11.

Lee, J. (1999). 'The inflation and output variability trade-off: evidence from a GARCH model', Economics Letters, Vol. 62, pp. 63-67.

Logue, D. and Sweeney, R. (1981). 'Inflation and real growth: some empirical results', Journal of Money, Credit, and Banking, Vol. 13, pp. 497-501.

Mallik, G. and Chowdhury, A. (2001). 'Inflation and economic growth: evidence from four South Asian countries', Asia-Pacific Development Journal, Vol. 1, pp. 123-135.

Pindyck, R. (1991). 'Irreversibility, uncertainty, and investment', Journal of Economic Literature, Vol. 29, pp. 1110-1148.

Speight, A. (1999). 'UK output variability and growth: some further evidence', Scottish Journal of Political Economy, Vol. 46, pp. 175-184.

Taylor, J. (1979). 'Estimation and control of a macroeconomic model with rational expectations', Econometrica, Vol. 47, pp. 1267-1286.

Temple, J. (2000). 'Inflation and growth: stories short and tall', Journal of Economic Surveys, Vol. 4, pp. 395-426.

Ungar, M. and Zilberfarb, B. (1993). 'Inflation and its unpredictability - theory and empirical evidence', Journal of Money, Credit, and Banking, Vol. 25, pp. 709-720.

Vilasuso, J. (2001). 'Causality tests and conditional heteroscedasticity: Monte Carlo evidence', Journal of Econometrics, Vol. 101, pp. 25-35. 